\title{
Low Sidelobe Level Microstrip Patch Array: EM Design and Performance Analysis
}

\author{
Manohar R. \\ Department of Telecommunication \\ CMR Institute of Technology \\ Bangalore, India \\ manoharsmrv@gmail.com
}

\author{
Maumita Dutta, Hema Singh \\ Centre for Electromagnetics (CEM) \\ CSIR-National Aerospace Laboratories \\ Bangalore 560017, India \\ duttamaumita123@gmail.com, hemasingh@nal.res.in
}

\begin{abstract}
A high performance low-profile antenna array with low sidelobe level (SLL) and optimum beamwidth is in general preferred in several communication related applications. In this paper a planar microstrip array antenna with low SLL up to -20 $\mathrm{dB}$ and high gain performance is designed for $10 \mathrm{GHz}$. The dimensions of patch antenna is tapered to achieve low SLL. The results for patch array with individual feed and a common feed are presented.
\end{abstract}

Keywords- Microstrip patch, phased array, reflection loss, radiation pattern

\section{INTRODUCTION}

The low observable technologies aim at reducing the scattering from the aerospace platforms to the least possible extent in order to shield it from the enemy radars. However, such low observable platform has consequence of sacrificing the antenna array performance in terms of gain and radiation characteristics. The phased array antenna can be designed efficiently to improve the performance as per the requirement. This requirement can be achieved by low-profile array [1].

The antenna array comprising of multiple antenna elements can be designed appropriately towards the desired radiation characteristics. The design parameters include the geometrical arrangement, inter-element spacing, element excitation amplitude and phase, individual element radiation pattern [2]. The amplitude and phase of excitation can control the beamwidth and sidelobe level (SLL). In particular SLL can be fixed by tapering the excitation across the antenna array. The smooth variation of taper in excitation from the centre element towards the end element results in reduction of SLL with broadening the mainlobe. In contrast from smaller beamwidth, the abrupt tapering is recommended. In open literature there are several array designs being proposed according to the requirement and applications.

A microstrip patch array is in general a preferred choice towards low profile phased array. A microstrip patch antenna (Fig. 1) is essentially a single-layer antenna comprising of a microstrip patch, non-conducting substrate, ground plane and the feed [3]. If the dimensions of the patch is tapered, the control over SLL may be achieved [4]. This concept has been exploited in this work. A rectangular patch is used to design an antenna array. The thickness of the patch is taken very small. The non-conducting low loss substrate is considered.



Fig.1. Schematic of microstrip patch antenna.

The dimension of a patch is tapered from the centre element to the end elements. A perfect electric conductor (PEC) ground plane is included in the design. The dimension of the feed line is taken smaller as compared to the patch towards good antenna performance. A planar array is made using linear array of microstrip patch with tapered dimensions. The array performance in terms of reflection loss and radiation pattern is analyzed. Two configurations, viz. array with individual feed and common feed are presented. It is shown that SLL up to $-20 \mathrm{~dB}$ can be achieved with desirable radiation characteristics.

\section{THEORETICAL BACKGROUND}

According to law of conservation of energy, if the side lobe level lowers than the main lobe widens resulting in broadening of beamwidth. This condition is suitable in some applications but for most of the application this is undesirable. The desired condition is low SLL with narrow beamwidth, which is feasible with an efficient array design. This is possible with tradeoff in array design parameters. A typical seven element series-fed tapered microstrip antenna array is shown in Fig. 2a. The array of such elements can be designed with different feed structure (Fig. 2). Here two configurations: (i) array with individual feed and (ii) array with common feed are considered.

\section{A. Designing a Rectangular Single Element Patch Antenna}

For designing a typical microstrip patch antenna, three parameters play important role namely frequency of operation, dielectric constant of the substrate and height of the dielectric substrate. The width of rectangular microstrip patch antenna is given by [5] 


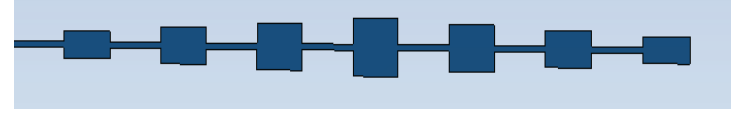

(a)

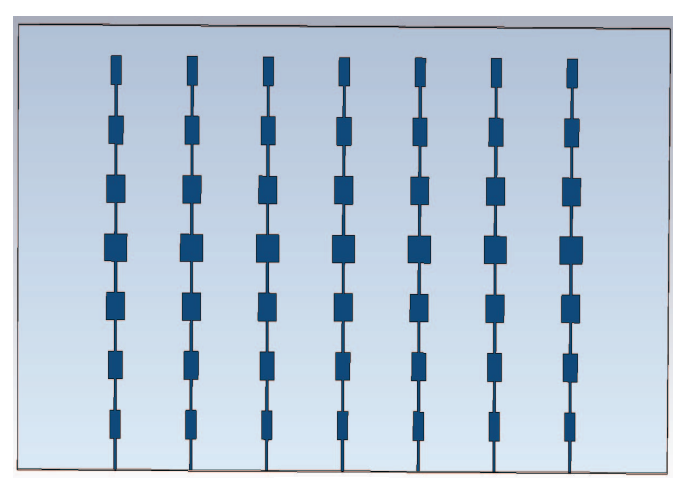

(b)

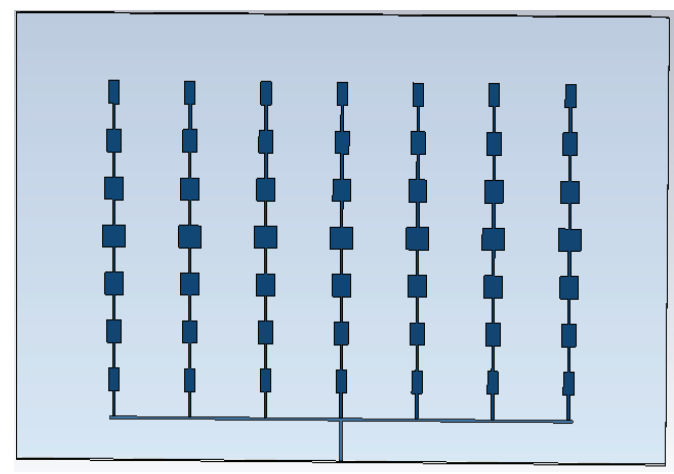

(c)

Fig.2. (a) $1 \times 7$ series-fed taper microstrip patch array, (b) $7 \times 7$ series-fed planar patch array with individual feeds, (c) $7 \times 7$ series-fed planar patch array with common feed.

$$
W=\frac{c}{2 f_{0} \sqrt{\frac{\left(\varepsilon_{r}+1\right)}{2}}}
$$

where, $W$ is the width of microstrip patch antenna, $c$ is the velocity of light in free space, $f_{o}$ is the frequency of operation, $\mathcal{E}_{r}$ is the dielectric constant of the substrate.

The effective dielectric constant is expressed as [1]

$$
\varepsilon_{\text {eff }}=\frac{\varepsilon_{r}+1}{2}+\frac{\varepsilon_{r}-1}{2} \sqrt{1+\frac{12 h}{w}}
$$

$\varepsilon_{\text {eff }}$ is the effective dielectric constant.

The effective length is given as

$$
L_{e f f}=\frac{c}{2 f_{0} \sqrt{\varepsilon_{e f f}}}
$$

The length extension is expressed as,

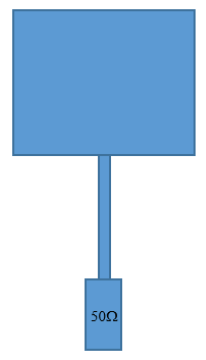

(a)

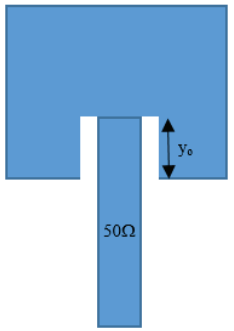

(b)
Fig.3. Patch antenna feed.

$$
\Delta L=0.412 h \frac{\left(\varepsilon_{e f f}+0.3\right)\left(\frac{w}{h}+0.264\right)}{\left(\varepsilon_{e f f}-0.258\right)\left(\frac{w}{h}+0.8\right)}
$$

Therefore, the actual length is given by

$$
L=L_{e f f}-2 \Delta L
$$

\section{B. Designing Microstrip Feed Line}

Microstrip feed line method is one of the widely used method for feeding antenna elements in phased arrays. The configuration and the dimensions of feed play critical role in the array performance, thus making its design an important step.

The impedance of the patch may be written as [5]

$$
Z_{a}=90 \frac{\varepsilon_{r}^{2}}{\varepsilon_{r}-1}\left(\frac{L}{W}\right)^{2}
$$

The characteristic impedance of transition section is given by

$$
Z_{T}=\sqrt{50+Z_{a}}
$$

The width of transition line is expressed as [6]

$$
Z_{T}=\frac{60}{\sqrt{\varepsilon_{r}}} \ln \left(\frac{8 d}{W_{T}}+\frac{W_{T}}{4 d}\right)
$$

$W_{T}$ is the width of the transition section. The length of the transition section is given by

$$
l=\frac{\lambda}{4}=\frac{\lambda_{0}}{4 \sqrt{\varepsilon_{e f f}}}
$$

Knowing the characteristic impedance of the feed and height of the substrate, the width of microstrip feed $(W)$ is obtained from

$$
Z_{o}=\frac{120 \pi}{\sqrt{\varepsilon_{\text {eff }}\left(1.393+\frac{W}{h}+\frac{2}{3} \ln \left(\frac{W}{h}+1.444\right)\right)}}
$$




\section{EM DESIGN OF ANTENNA ARRAY}

Once all the essential design parameters are known, the array can be designed using full wave simulation software. In this paper first a $1 \times 7$ series feed taper patch array is designed. This $1 \times 7$ linear array is then extended to obtain a planar $7 \times 7$ series-fed taper patch array having individual feeds. Then another $7 \times 7$ series-fed taper patch array is designed with a single feed towards reducing the losses and hence improving array performance.

\section{A. A Linear $1 \times 7$ Series-fed Taper Patch Array}

This antenna contains seven patch elements with different dimensions. The length and width of the patch elements are tapered from centre patch to the end patch element. A common strip joins all the patches forming an antenna feed. The dimensions of each patch antenna element is given in Table I.

TABLE I: DIMENSIONS OF THE ANTENNA ELEMENTS IN THE ARRAY

\begin{tabular}{|c|l|l|l|l|}
\hline Element & $\begin{array}{c}\text { Patch } \\
\text { width } \\
\mathbf{( m m})\end{array}$ & $\begin{array}{c}\text { Patch } \\
\text { length } \\
\mathbf{( m m})\end{array}$ & $\begin{array}{c}\text { Line } \\
\text { length } \\
\mathbf{( m m})\end{array}$ & $\begin{array}{c}\text { Line } \\
\text { width } \\
\mathbf{( m m})\end{array}$ \\
\hline 1 & 4.8 & 10.13 & 11.12 & 1.11 \\
\hline 2 & 6.55 & 9.93 & 11.12 & 1.11 \\
\hline 3 & 8.39 & 9.79 & 11.12 & 1.11 \\
\hline 4 & 10.35 & 9.68 & 11.12 & 1.11 \\
\hline 5 & 8.39 & 9.79 & 11.12 & 1.11 \\
\hline 6 & 6.55 & 9.93 & 11.12 & 1.11 \\
\hline 7 & 4.8 & 10.13 & 11.12 & 1.11 \\
\hline
\end{tabular}

The designed structure of the linear patch array is shown in Fig. 4. The substrate material is taken as Rogers RT5880 having a dielectric constant of 2.2 and the height of $0.79 \mathrm{~mm}$. A PEC ground plane is included below the substrate. The material of the patch as PEC. The antenna is excited using wave port. The dimension of the waveport is obtained from

$$
W^{\prime}=6 W_{f} ; H^{\prime}=5 h+M_{t}
$$

Here, $\left(H^{\prime}, W^{\prime}\right)$ is the height and width of the waveport respectively, $h$ is the height of the substrate, $W_{f}$ is the width of the feed, and $M_{t}$ is the height of the ground plane.

\section{B. A $7 \times 7$ Planar Series-Fed Taper Patch Array with Individual Feeds}

Extending the above $1 \times 7$ linear patch array, a $7 \times 7$ planar patch array is designed. The spacing between two linear arrays is taken as $35 \mathrm{~mm}$.

The designed array is shown in Fig. 5. The array is excited using waveport.

\section{A $7 \times 7$ Series-fed Taper Patch Array having Common Feed}

In this design, unlike Fig. 5, where each linear array was having individual feeds, all the linear arrays have a common feed. The designed array with common feed is shown in Fig. 6. The array is excited using waveport.

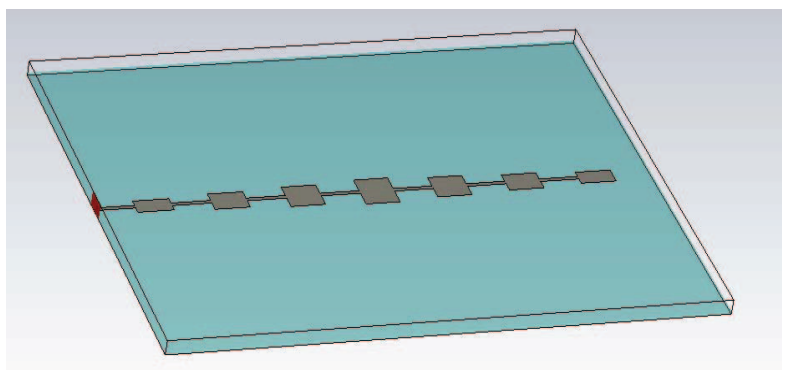

Fig.4. A 1×7 Series Fed Taper Antenna Array

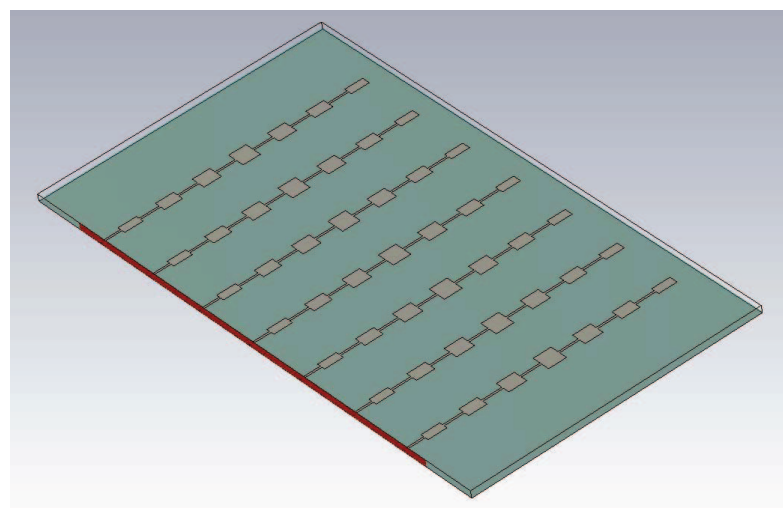

Fig.5. A $7 \times 7$ Series-fed Taper Patch Array with Individual Feeds

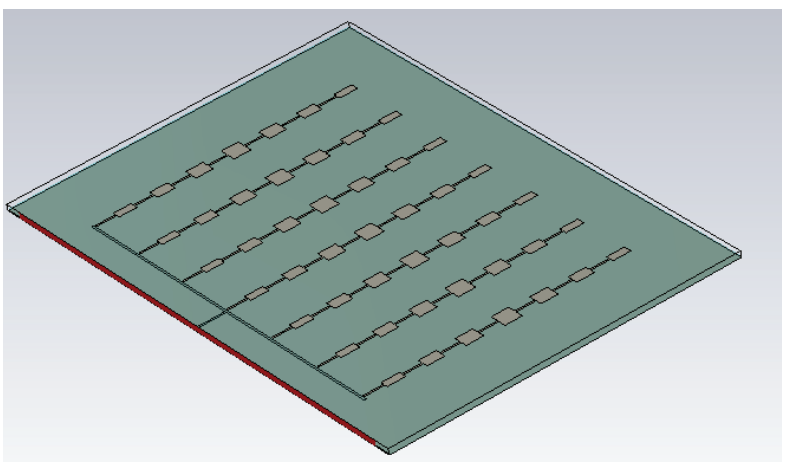

Fig.6. A $7 \times 7$ Series-fed Taper Antenna Array with a Common Feed

\section{PERFORMANCE ANALYSIS}

In this section the performance analysis of the designed antenna arrays in terms of reflection $\operatorname{loss}\left\{=20 \log _{10}\left(S_{11}\right)\right\}$ and radiation pattern are discussed.

\section{A. A Linear $(1 \times 7)$ Series Fed Taper Antenna Array}

The reflection loss of the designed linear series-fed taper patch array is shown in Fig. 7. The operating frequency is taken to be $10 \mathrm{GHz}$. The reflection loss obtained in within $-10 \mathrm{~dB}$, which is not very good. However it is expected that when this patch array would be extended to planar configuration, the reflection loss will improve. 


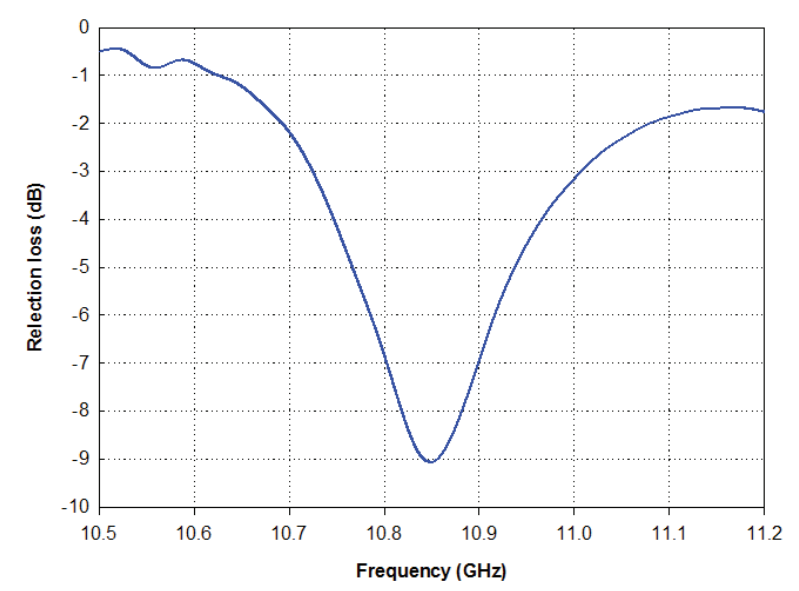

Fig.7. Reflection loss of a $1 \times 7$ Linear Series-fed Taper Patch Array



Fig.8. Far-field Radiation Pattern of a Linear $1 \times 7$ Series-fed Taper Patch Array

The radiation pattern of the linear array is shown in Fig. 8. The SLL is observed to be better than $-10 \mathrm{~dB}$. This performance would improve further for planar configuration. The $3 \mathrm{~dB}$ beamwidth obtained is 11 degrees.

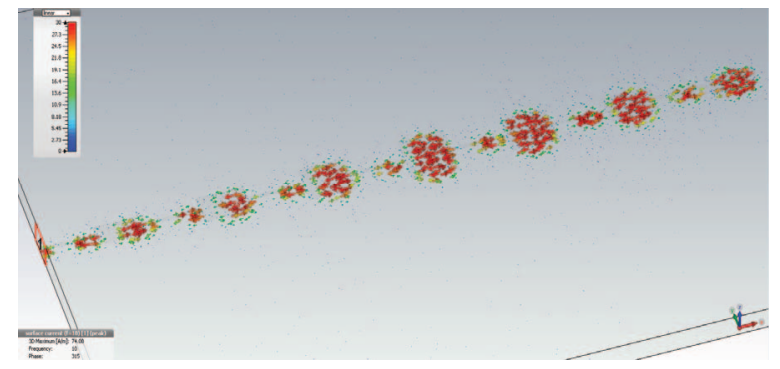

Fig.9. Surface Current Distribution in a Linear $(1 \times 7)$ Series-fed Taper Patch Array

The surface current distribution over the excited linear array is shown in Fig. 9. The corresponding E-field and $\mathrm{H}$-field distributions over the array are presented in Fig. 10 and Fig. 11 respectively.

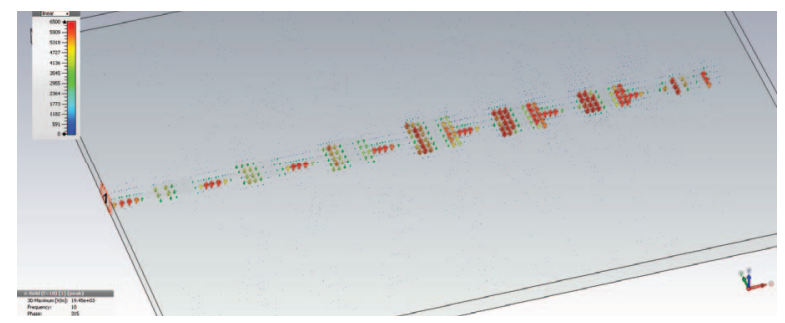

Fig.10. E-Field of 1x7 Series Fed Taper Antenna Array

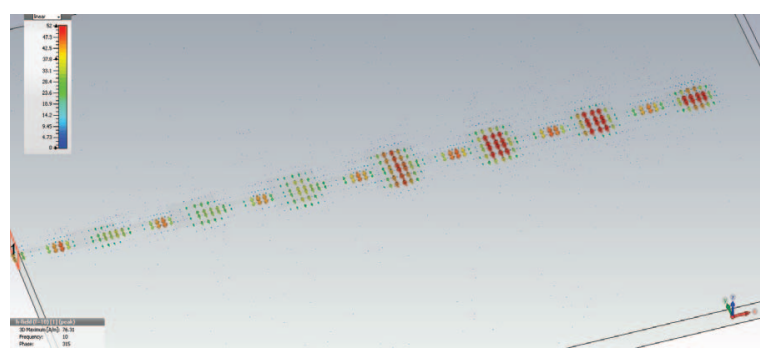

Fig.11. H-Field of 1x7 Series Fed Taper Antenna Array

\section{B. A Planar (7×7) Series-fed Taper Patch Array having Individual Feeds}

The reflection loss of the designed planar series-fed taper patch array is shown in Fig. 12. It may be observed that reflection loss obtained is well below $-20 \mathrm{~dB}$, as expected. The operating frequency is $10 \mathrm{GHz}$. Fig. 13 presents the radiation pattern of the designed planar patch array. The $3 \mathrm{~dB}$ beamwidth in the radiation pattern is 10.6 degrees. The SLL obtained in better than $-20 \mathrm{~dB}$ from the mainlobe. As expected that the performance in terms of SLL got improved significantly in case of planar patch array with tapered patch dimensions. The surface current distribution over the excited linear array is shown in Fig. 13. The corresponding E-field and H-field distributions over the array are presented in Fig. 14 and Fig. 15 respectively.



Fig.12. Reflection Loss of a Planar $(7 \times 7)$ Series-fed Taper Patch Array with Inividual Feeds. 


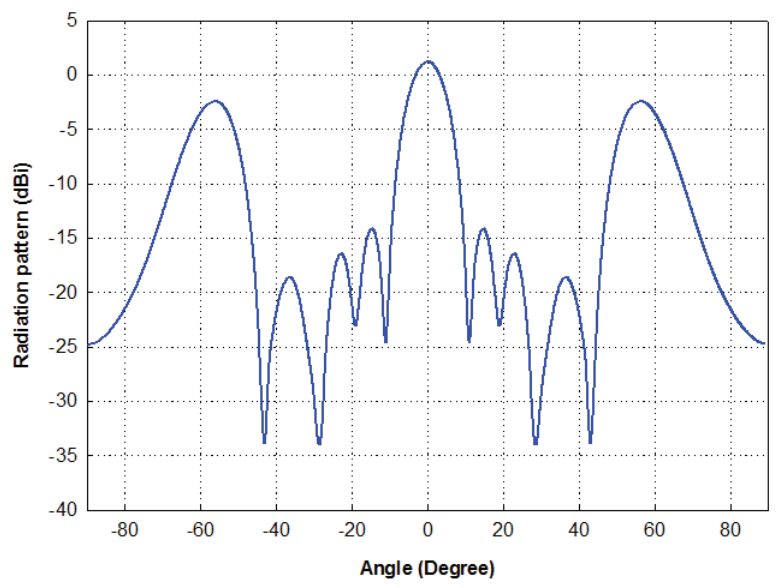

Fig.13. Radiation Pattern of a Planar $(7 \times 7)$ Series-fed Taper Patch Array with Inividual Feeds.



Fig. 14. Surface Current Distribution over a Planar $(7 \times 7)$ Series-fed Taper Patch Array with Inividual Feeds.

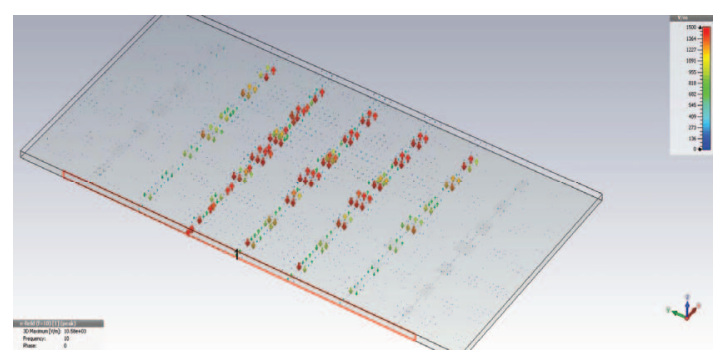

Fig.15. E-Field distribution over a Planar $(7 \times 7)$ Series-fed Taper Patch Array with Inividual Feeds.



Fig.16. H-Field distribution over a Planar $(7 \times 7)$ Series-fed Taper Patch Array with Inividual Feeds.

\section{A Planar $7 \times 7$ Series-fed Taper Patch Array having Common Feed}

The reflection loss of the designed planar series-fed taper patch array with common feed is shown in Fig. 17. It may be observed that reflection loss obtained is well below $-20 \mathrm{~dB}$. The operating frequency is $10 \mathrm{GHz}$. Fig. 18 presents the radiation pattern of the designed planar patch array with common feed. The $3 \mathrm{~dB}$ beamwidth is 7 degrees. The SLL obtained in better than $-26 \mathrm{~dB}$ from the mainlobe. This corroborates the improvement in array performance when the individual feeds are replaced by a common feed. This enhancement in array performance is due to the reduction of losses within the array system when common feed is used.



Fig.17. Reflection Loss of a Planar $(7 \times 7)$ Series-fed Taper Patch Array with Common Feed.

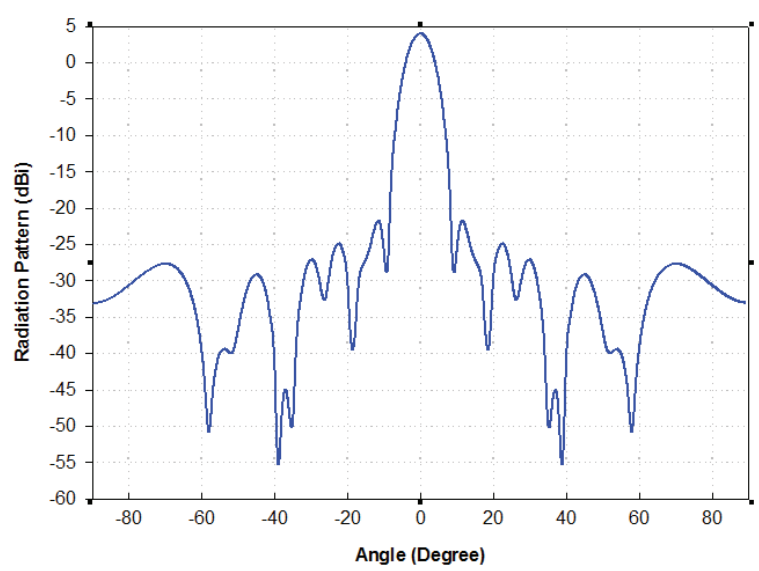

Fig.18. Radiation Pattern of a Planar $(7 \times 7)$ Series-fed Taper Patch Array with Common Feed.

\section{CONCLUSION}

Using the concept of tapering the antenna dimensions for enhancement in array performance, an efficient patch array is designed towards reduced SLL and optimum beamwidth. The results are shown for tapered patch array with two types of feed, viz. individual feed and common feed. The lower side lobes are obtained due to the uniform tapering nature of the $1 \times 7$ antenna array. The smooth variation of taper in excitation from 
the centre element towards the end element results in reduction of side lobe level with broadening the mainlobe. In contrast from smaller beamwidth, the abrupt tapering is recommended.

\section{ACKNOWLEDGMENT}

We express our thanks to Department of Electronics, Cochin University of Science and Technology (CUSAT), Kochi, India for providing full wave simulation software facility.

\section{REFERENCES}

[1] A. De, C. K. Chosh and A. K. Bhattacherjee, "Design and perfoemance analysis of microstrip patch array antennas with different configurations," International Journal of Future Generation Communication and Networking, vol. 9, no. 3 pp. 97-110, 2016.
[2] C. A. Balanis, Äntenna Theory, analysis and Design, 3rd ed., John Willey\& Sons, ISBN: 0-471-66782-X, 1117 p., 2005.

[3] R. Garg, P. Bhartia, I. Bhal and A. Ittipiboon, Microstrip Antenna Design Handbook, Artech House, Boston, London, ISBN: 0-89006-5136, 845 p., 2001.

[4] A. Rida, M. Tentzeris and S. Nikolaou, "Design of Low Cost Microstrip Antenna Arrays for mm-Wave Applications," Antennas and Propagation (APSURSI), IEEE International Symposium, pp. 2071-2073, 3-8 July 2011, Spokane,WA.

[5] D. M. Pozar and D. H. Schuabert, Microstrip Antennas: The Analysis and Design of Microstrip Antennas and Arrays, John Willey\& Sons, ISBN: 0-7803-1078-0, 431 p., 1995.

[6] S. Bisht, A. Singh, R. Chauhan and G. Pant, "Implementation and Applications of Feeding Techniques Using CST Microwave Studio," International Journal on Recent and Innovation Trends in Computing and Communications (IJRITCC), vol. 2, issue. 6, pp .1754-1760 June 2014 